\title{
Projeto de Extensão: curso de introdução à programação para crianças do ensino fundamental
}

\author{
Luciene Cavalcanti Rodrigues ${ }^{1,2}$, Ana Paula Garrido de Queiroga ${ }^{3}$, Manassés \\ Vitorino de Oliveira ${ }^{1}$, Alessandro Tetsuo More ${ }^{1}$ \\ ${ }^{1}$ Instituto de Federal de Educação, Ciência e Tecnologia de São Paulo (IFSP) \\ Campus Votuporanga \\ Av. Jerônimo Figueira da Costa, 3014 - Pozzobon - Votuporanga, SP - Brasil \\ Grupo de Pesquisa CNPq: Tecnologias e práticas inovadoras aplicadas ao ensino \\ ${ }^{2}$ Faculdade de Tecnologia de São José do Rio Preto (Fatec) \\ Centro Estadual de Educação Tecnológica Paula Souza \\ Rua Fernandópolis, 2510 - Eldorado - S. J. Rio Preto, SP - Brasil \\ ${ }^{3}$ União das Faculdades dos Grandes Lagos - UNILAGO
}

prof.luciene@ifsp.edu.br,anaproj.eng@gmail.com,manavitorino@gmail.com, alemore67@gmail.com

\begin{abstract}
Children are learning all the time, through numerous activities inside and outside the classroom, making them more autonomous, self-taught, able to solve problems and work in teams. In this context, children should not consume only technology but building it in this way, this article reports the game programming teaching experience using Scratch with a first group of 16 children 9-10 years of a municipal school in conjunction with the Instituto Federal de Educação, Ciência e Tecnologia de São Paulo, in a second group (2017) possible to improve the content of the classes and develop a cultural show with the participation of the community.
\end{abstract}

Resumo. Crianças estão aprendendo a todo momento, por meio de inúmeras atividades dentro e fora da sala de aula, tornando-os mais autônomos, autodidatas, capazes de resolver problemas e trabalhar em equipe. Neste contexto, as crianças não devem apenas consumir tecnologia e sim construíla, desta forma, este artigo relata a experiência de ensino de programação de jogos utilizando Scratch com a primeira turma de 16 crianças de 9 a 10 anos de uma escola municipal em conjunto com o Instituto Federal de Educação, Ciência e Tecnologia de São Paulo, em sua segunda turma (2017) será possivel aprimorar o conteúdo das aulas e desenvolver uma mostra cultural com a participação da comunidade.

\section{Introdução}

As Tecnologias Digitais de Informação e Comunicação (TDIC), são cada vez mais utilizadas tendo em vista a ampliação do aprendizado e a possibilidade de mudanças diárias no âmbito educacional (Costa, Aguiar e Magalhães 2013, apud Aguiar, 2014). 
Para Mota et al (2014), é de conhecimento geral que a computação vai além do uso do computador para a realização de atividades rotineiras, podendo ser utilizado no desenvolvimento de novos programas ou jogos com diferentes funcionalidades, uma atividade que envolve conhecimentos de lógica de programação que podem ser aplicados em várias áreas, não se limitando a informática.

Entre os campos da educação, da comunicação social e da literatura, a tecnologia dos jogos eletrônicos para o primeiro representa uma promessa de aproximação dos sistemas de ensino em relação a tecnologia informacional contemporânea, para o segundo representa a emergência de uma nova mídia enquanto para o terceiro mostra-se uma enigmática forma textual a qual ainda bastante atrelada ao paradigma do impresso (Aranha, 2006, p.105-106).

Dentro deste contexto, este artigo visa relatar a experiência com a execução do projeto de extensão com carga horária de 32 horas intitulado "Introdução a Programação para Crianças" que contou com 16 crianças de 9 a 10 anos, matriculadas na Escola Municipal Neyde Marão da cidade de Votuporanga. Serão relatados no decorrer do artigo aspectos pedagógicos, tecnológicos, a metodologia do curso e os resultados obtidos e as perspectivas para a segunda turma.

\section{Metodologia e Atividades Realizadas}

Segundo o trabalho de Gresse von Wangenheim, Nunes e Santos (2014) toda criança deve ter a oportunidade de aprender computação desde o Ensino Fundamental. Observase que o Ensino Fundamental foca somente no ensino da utilização de TI (IT literacy ou alfabetização digital), o que não é mais suficiente, sendo necessário ensinar a proficiência digital (IT fluency), acrescentando a capacidade de aprender e aplicar as novas tecnologias de forma produtiva ao longo da vida profissional/pessoal.

Visando criar um ambiente lúdico e com foco no ensino de proficiência digital, o curso de Extensão "Introdução à Programação para Crianças" foi realizado nos laboratórios do Instituto Federal de Educação, Ciência e Tecnologia de São Paulo (IFSP), contando com carga horária total de 32 horas, separadas em encontros semanais com duração de 2 horas. Semanalmente as 16 crianças da Escola Municipal Neyde Marão, dois técnicos em informática que trabalham na escola e dois bolsistas do IFSP participaram, juntamente com a professora responsável pelo projeto das atividades do curso...

\section{Resultados (Turma 1)}

O curso foi realizado com o uso de salas de aula e laboratórios de Informática, contando com várias atividades fora do computador, como a montagem dos comandos necessários (recortados em EVA e disponíveis todos misturados) para que o personagem passe por todo o labirinto e chegue ao destino. A recompensa para a conclusão deste desafio era um saquinho com guloseimas para os alunos. Também foram realizadas atividades práticas no computador, tais como pesquisas na internet e criação dos jogos utilizando o Scratch, que visam aliar diversas atividades e desafios para os alunos, lembrando sempre que o computador é um "meio" e não um "fim" em si, ele ajuda a criar os jogos e não pensa sozinho, o aluno deve raciocinar sobre o jogo, elencar as regras e depois definir os comandos necessários para que os personagens executem o desejado. 
VI Congresso Brasileiro de Informática na Educação (CBIE 2017)

Anais do XXIII Workshop de Informática na Escola (WIE 2017)

Como atividades da aula inicial os alunos receberam uma cartolina com um labirinto desenhado, uma cartolinha em branco, um personagem (que foi escolhido pelos alunos após um teste com 25 expressões matemáticas) e em outra mesa estavam misturados vários comandos MOVA e GIRE (similares aos do Scratch). Os alunos deveriam colocar o personagem no início do labirinto e separar o conjunto de comandos necessários para que o personagem chegasse ao final para receber o prêmio.

$\mathrm{Na}$ primeira aula no laboratório de informática foi demostrado como tudo funcionava, não foi preciso ensinar como ligar ou desligar o computador, ou como acessar a internet, foi mostrado o acesso ao site do Scratch e realizada a primeira animação de um personagem dançando. $\mathrm{O}$ impacto da ferramenta foi muito motivador, os alunos gostaram muito de arrastar e soltar alguns blocos e o personagem começar a dançar na tela. Posteriormente foram editados o palco, sons e foi gravada cada animação com uso de usuário e senha. Na aula seguinte os alunos novamente foram agrupados para executar o desenho e criação dos comandos para que o personagem percorra o labirinto (Figuras 1a e 1b).

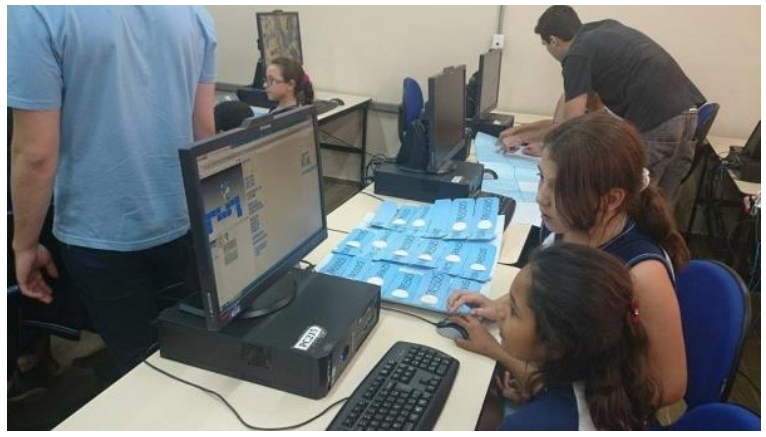

Figura 1. a) Programação do labirinto

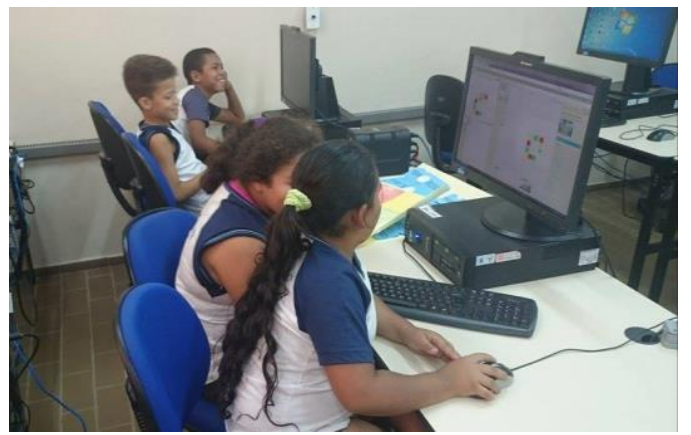

b) Discussões em grupo

Para os demais jogos os alunos recebiam um tutorial impresso (sempre com no máximo 4 páginas) com a aula (jogo) a ser desenvolvido contendo um ou mais desafios. A cada aula os jogos foram ficando mais complexos, a fim de exemplificar o uso completo da ferramenta e desenvolver o raciocínio lógico e a capacidade de resolução de problemas (Figuras 2 a e b).

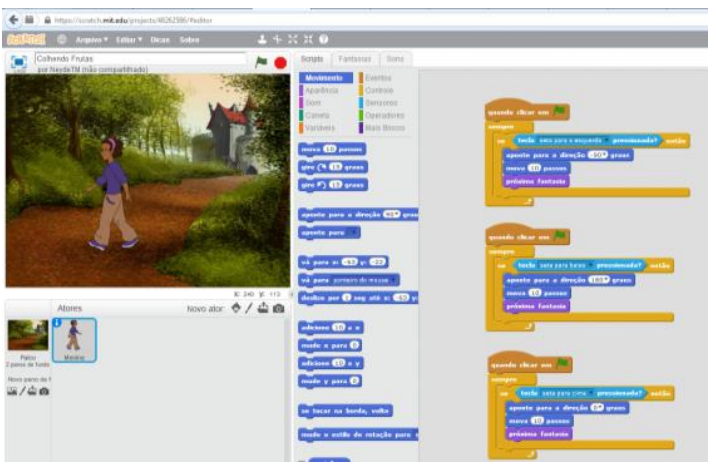

Figura 2. a) Colhendo Frutas

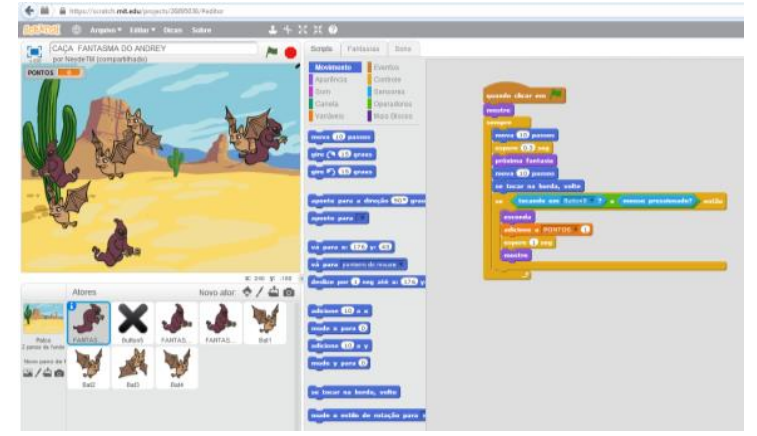

b) Caça-fantasmas

\section{Conclusões}

De acordo com a Partnership for the 21st Century (2003), o ambiente apoia o desenvolvimento de habilidades de aprendizagem do século XXI, onde os autores destacam as formas como Scratch suporta o desenvolvimento de tais habilidades: 
Habilidades de informação e comunicação, por meio da seleção, criação e gerenciamento múltiplas formas de mídia, incluindo texto, imagens, animações e gravações de áudio, tornando-se mais perspicazes e críticos ao analisar os meios de comunicação que veem ao redor deles. Desenvolvem habilidades de pensar e resolver problemas pois à medida que aprendem a programar, os estudantes aprimoram seu raciocínio crítico e pensamento sistemático no desenvolvimento de suas soluções, encorajando o pensamento criativo ao envolver os aprendizes na busca de soluções inovadoras para problemas, não apenas aprender a resolver um problema predefinido, mas estar preparado para chegar a novas soluções para os desafios que surgirem.

Nota-se que na experiência relatada neste trabalho, é possível aliar conteúdos teóricos ao desenvolvimento de aplicações práticas, como por exemplo, o jogo de reciclagem e a animação de um livro, tornando o processo de ensino-aprendizagem mais lúdico e centrado no estudante, utilizando várias habilidades, criatividade e interesse dos alunos e professores. Foram realizadas duas avaliações de múltipla escolha, uma no meio do curso e outra ao final, contendo questões de raciocínio e matemática, as notas em si não foram o propósito da avaliação mas sim avaliar a melhora no raciocínio lógico das crianças, sendo possível afirmar que $80 \%$ dos alunos melhoraram seu desempenho em relação à avaliação anterior.

Para a segunda turma serão incorporadas mais 8 horas de aula, visando o design e criação de um projeto próprio do aluno, contando com a confecção de storyboard, áudio e imagens do jogo que será apresentado na mostra cultural durante a semana nacional de ciência e tecnologia. Também já foram recriadas as aulas, contendo vídeos, mais desafios e atividades avaliativas a cada aula, bem como a realização de avaliações diagnósticas no início, meio e final do projeto, visando aperfeiçoamento contínuo do projeto.

\section{Referências}

AGUIAR, J. J. B.; FECHINE, J. M.; COSTA, E. B. (2014). Estilos Cognitivos e Estilos de Aprendizagem em Informática na Educação: um mapeamento sistemático focado no SBIE, WIE e RBIE. Disponível em: <http://www.brie.org/pub/index.php/sbie/article/view/2972/2705>

ARANHA, G. (2006). Jogos Eletrônicos como um conceito chave para o desenvolvimento de aplicações imersivas e interativas para o aprendizado. Ciênc. cogn. [online]. 2006, vol.7, n.1, pp. 105-110. Acesso em: 12 jul. 2014.

GRESSE VON WANGENHEIM, C.; NUNES, V. R.; SANTOS, G. D. (2014). Ensino de Computação com SCRATCH no Ensino Fundamental - Um Estudo de Caso. Revista Brasileira de Informática na Educação, [S.1.], v. 22, n. 03, p. 115, nov. 2014. ISSN 1414-5685. Disponível em: <http://www.brie.org/pub/index.php/rbie/article/view/2885>. Acesso em: 12 Mai. 2015.

MOTA, F. P. et al. Desenvolvendo o Raciocínio Lógico no Ensino Médio: uma proposta utilizando a ferramenta Scratch. In: Anais do $25^{\circ}$. Simpósio Brasileiro de Informática na Educação. $3^{\circ}$. Congresso Brasileiro de Informática na Educação. Nov. 2014. Dourados, MS. Disponível em: < http://www.brie.org/pub/index.php/sbie/article/view/2964/2698> 